\title{
Patients' experiences of prescribed anti-obesity drugs and perceptions of support from primary care: a qualitative study
}

\author{
Aikaterini Psarou ${ }^{1, a}$ and lan Brown ${ }^{2}$ \\ ${ }^{1}$ Senior Lecturer in Dietetics, Department of Biological Sciences, University of Chester, Parkgate Road, Chester, UK \\ ${ }^{2}$ Senior Lecturer, Faculty of Health and Wellbeing, Sheffield Hallam University, South Yorkshire, UK
}

\begin{abstract}
Aim: To explore the views and experiences of obese patients prescribed anti-obesity drugs in primary care, including their understanding of guidance about lifestyle changes. Background: Pharmacotherapy treatments are increasingly used to support obesity management. Currently, two anti-obesity drugs are available on the National Health Service (NHS): Orlistat and Sibutramine. Although detailed clinical guidelines for their use are well documented, there is little research about how obese individuals experience and view these drugs in routine care. Methods: Qualitative design with semi-structured interviews conducted in participants' homes or a health centre. Participants recruited from three general practices in Sheffield with socio-economically diverse populations using purposive sampling. Interviews transcribed verbatim and analysed using the 'framework' approach. Findings: Health concerns are the key factor for patients seeking help with weight loss. Participants are typically ambivalent about taking anti-obesity drugs and expectations vary from unreasonably sceptical to unreasonably optimistic. There appears to be high awareness of the need for lifestyle change. Those prescribed Orlistat understood how it worked, however, those on Sibutramine and Rimonabant did not. Participants' experiences in taking anti-obesity drugs varied greatly and changed with experiences of weight loss, side effects and quality of support. Most could identify points at which the information, choice and support provided by primary care could be improved. However, most were not aware of other avenues of support. Conclusion: This study has identified a number of areas for service improvement. Better understanding of patient expectations around anti-obesity drugs should help the NHS to shape services to meet needs and make the experiences of patients more positive.
\end{abstract}

Key words: anti-obesity drugs; obesity; primary health care; qualitative research

Received 20 October 2008; accepted 3 March 2010; first published online 18 May 2010

\section{Introduction}

In the UK, almost a quarter of adults are currently classified as obese and this is predicted to rise substantially if current trends remain unchanged

Correspondence to: Aikaterini Psarou, Senior Lecturer in Dietetics, Department of Biological Sciences, University of Chester, Parkgate Road, Chester, CH1 4BJ, UK. Email: k.psarou@chester.ac.uk

${ }^{\text {a }}$ Post during this work: Advanced Dietetic PractitionerCommunity, Sheffield Primary Care Trust.
(Foresight, 2007). Within the National Health Service (NHS), primary care is the key provider of support and appropriate treatment for people who are obese, including the prescription of antiobesity drugs (Department of Health, 2006). However, the increasing prevalence of obesity puts additional pressure on General Practitioners' (GP) and Practice Nurses' (PN) time; in part because obese people have more contacts (across a range of problems) than 'normal weight' counterparts (Counterweight Project Team, 2005). Not surprisingly, then, other research suggests that the quality 
Table 1 Anti-obesity drugs clinical information

\begin{tabular}{|c|c|c|c|}
\hline & Orlistat & Sibutramine & Rimonabant \\
\hline Mode of action & $\begin{array}{l}\text { A pancreatic and gastric lipase } \\
\text { inhibitor resulting in decrease } \\
\text { of absorption of fat by } 30 \%\end{array}$ & $\begin{array}{l}\text { A serotonin and noradrenaline } \\
\text { re-uptake inhibitor promoting a } \\
\text { sense of satiety }\end{array}$ & $\begin{array}{l}\text { An endocannabinoid (CB1) } \\
\text { receptor antagonist affecting } \\
\text { energy balance, glucose and } \\
\text { lipid metabolism and } \\
\text { modulating the intake of } \\
\text { sweet/fatty foods }\end{array}$ \\
\hline Dose/regime & $\begin{array}{l}120 \mathrm{mg} \text { three times daily with } \\
\text { water immediately before, } \\
\text { during or up to one hour after } \\
\text { each meal }\end{array}$ & $\begin{array}{l}10-15 \text { mg once daily, usually } \\
\text { taken in the morning with } \\
\text { liquid, with/ without food }\end{array}$ & $\begin{array}{l}20 \mathrm{mg} \text { once daily, usually } \\
\text { taken before breakfast }\end{array}$ \\
\hline Lifestyle changes & $\begin{array}{l}\text { Reduced calorie diet, behaviour } \\
\text { modification and exercise }\end{array}$ & $\begin{array}{l}\text { Reduced calorie diet, behaviour } \\
\text { modification and exercise }\end{array}$ & $\begin{array}{l}\text { Reduced calorie diet and } \\
\text { exercise }\end{array}$ \\
\hline Duration & $\begin{array}{l}\text { Up to four years or as long as } \\
\text { patient is losing weight }\end{array}$ & One-year licence & $\begin{array}{l}\text { Currently suspended } \\
\text { Licence was up to two years }\end{array}$ \\
\hline Efficacy & Reduces weight by $2.9 \mathrm{~kg}$ & Reduces weight by $4.2 \mathrm{~kg}$ & Reduces weight by $4.7 \mathrm{~kg}$ \\
\hline Side effects & $\begin{array}{l}\text { Headaches, abdominal pain, } \\
\text { oily spotting, faecal urgency, } \\
\text { fatty/oily stools, increase } \\
\text { defaecation - these are } \\
\text { proportional to fat content of } \\
\text { the diet }\end{array}$ & $\begin{array}{l}\text { Tachycardia, palpitations, } \\
\text { hypertension, constipation, } \\
\text { insomnia, nausea, dry mouth, } \\
\text { sweating }\end{array}$ & $\begin{array}{l}\text { Nausea, dizziness, } \\
\text { diarrhoea, insomnia, } \\
\text { depression, mood } \\
\text { alternations, suicidal } \\
\text { thoughts, anxiety }\end{array}$ \\
\hline Overdose & $\begin{array}{l}\text { No adverse events or similar } \\
\text { side effects with doses of } \\
240-800 \mathrm{mg} \text {, but requires } \\
\text { monitoring }\end{array}$ & $\begin{array}{l}\text { Most frequent adverse events } \\
\text { are tachycardia, hypertension, } \\
\text { headache and dizziness and } \\
\text { requires monitoring }\end{array}$ & $\begin{array}{l}\text { No adverse events or similar } \\
\text { side effects with doses of } \\
180-300 \mathrm{mg} \text {, but requires } \\
\text { monitoring }\end{array}$ \\
\hline Contra-indications & $\begin{array}{l}\text { Malabsorption or chronic } \\
\text { gastrointestinal disease. } \\
\text { Reduces absorption of } \\
\text { amiodarone, ciclosporin and } \\
\text { can effect warfarin. May impair } \\
\text { absorption of fat-soluble } \\
\text { vitamins (A, D, E and K). }\end{array}$ & $\begin{array}{l}\text { Uncontrolled hypertension, } \\
\text { tachycardia, palpitation, anti- } \\
\text { depressants/anti-psychotic } \\
\text { medications, liver and renal } \\
\text { impairment, hyperthyroidism, } \\
\text { eating disorders. }\end{array}$ & $\begin{array}{l}\text { Mental illness and liver } \\
\text { impairment }\end{array}$ \\
\hline
\end{tabular}

Source: SPC, 2006, 2007, 2009; Rucker et al., 2007.

of weight management support provided in primary care is patchy in quality (National Audit Office, 2001; Dr Foster, 2005) and may not meet the expectations of service users (Brown et al., 2006). There is increased interest, therefore, in how primary care can provide responsive and effective health care services for people who are obese, including the prescription of anti-obesity drugs (Department of Health, 2005; 2008).

Although lifestyle and behavioural interventions are a first line of management, anti-obesity drugs are recommended when patients have failed to reach target weight loss or have reached a plateau or are in urgent medical need to lose weight. These drugs act in different ways, either on the gastrointestinal system [Orlistat] or on the central nervous system [Sibutramine and Rimonabant] (Padwal and Majumdar, 2007) and a range of side effects are reported (Table 1). They have been shown to be effective for weight loss (Rucker et al., 2007) and recent guidelines have recommended their prescription combined with healthy lifestyle changes (National Institute of Clinical Excellence, 2006). However, since October 2008, Rimonabant's licence has been suspended due to adverse side effects (MHRA, 2008). Currently, two anti-obesity drugs are available on the NHS: Orlistat and Sibutramine.

Overall, there is little research into the experiences of patients who have been prescribed these anti-obesity drugs in routine care. One previous UK study (Ogden and Sidhu, 2006) examined patients' experiences of taking Orlistat but not the experiences of primary care or of the other medications. The aims of this study, therefore, were to explore the views and experiences of 
patients prescribed any of the three anti-obesity drugs, including support they received in primary care, and their understanding of guidance about lifestyle changes.

\section{Method}

\section{Design and setting}

The study employed a qualitative design with semi-structured interviews (Richie and Lewis, 2003). Project management, interview guide design and data analysis were undertaken with the support of two lay team members, each with personal experience of anti-obesity drugs. This user involvement is considered to increase the validity of the study findings (Staley, 2009).

Following ethics approval, participants were recruited from three general practices in Sheffield using a purposive sampling strategy; aiming to achieve a symbolic diversity of social backgrounds (Richie et al., 2003). The three practices were approached due to their relatively high prescription of anti-obesity drugs at the time of the study and the socio-economic diversity of the populations they served.

\section{Sampling and recruitment}

The participants were aged between $18-75$ years with a body mass index of $27 \mathrm{~kg} / \mathrm{m}^{2}$ and above, and had been taking a prescribed anti-obesity drug for at least two months within the previous two years. These criteria were used as they represent basic indications for being commenced on anti-obesity drugs (National Institute of Clinical Excellence, 2006). At least two-month experience ensured good participant recall and the inclusion of varied stages of experience from recent commencement through to completion of treatment.

Participating general practices used computerised prescription records to identify suitable patients, excluding those with mental health problems and those unable to conduct an interview in English. Potential participants were contacted by the practice by post to invite participation in the study. Overall, 200 patients were contacted in this way and about 50 registered their interest in an interview. In total, 31 patients were interviewed (by A.P.) at their own home or at a health centre between July and October 2007. Data collection ceased following the 31 interviews as no new themes were emerging (saturation). A summary of the sample characteristics is shown in Table 2. At the time of the study, Rimonabant was relatively new to the market and appears, therefore, to be prescribed less frequently than the other two drugs, particularly Orlistat.

\section{Interviews and analysis}

Interviews followed a flexible question guide (Box 1) and typically lasted around 35 minutes. All were digitally recorded with participants' consent. Recordings were transcribed verbatim and identifying text anonymised. These data were then entered to QSR NVivo (QSR International (UK) Limited, Southport, UK), a data management and

Table 2 Characteristics of study participants $(n=31)$

\begin{tabular}{lc}
\hline Sample characteristics & \\
Sex & \\
Male & 9 \\
Female & 22 \\
Mean age in years (range) & 53 (26-72) \\
In employment & 16 \\
Yes & 15 \\
No & \\
Medication treatment & \\
Orlistat & 28 \\
Sibutramine & 9 \\
Rimonabant & 2 \\
\hline
\end{tabular}

a Six patients had had more than one anti-obesity drug (four had Orlistat and Sibutramine, two had all three drugs), however, these were taken at different times.

\section{Box 1 Themes covered in interview schedule}

Weight history and perceptions of weight as a problem

- Chronological story of weight management within primary care service

- Introduction to weight loss medication and expectations

- Interaction with health professionals whilst taking weight loss medication

- Experiences of medication use and effects on daily life (side effects)

- Perceptions of outcomes

- Perceptions of support provided

- Potential help and support 
analysis programme. The transcripts were analysed to identify themes using an established qualitative analysis approach developed in Britain for policy research (Richie and Lewis, 2003). This 'framework' approach consists of five steps; identification of descriptive codes from independent repeated readings of transcripts, then identification of emerging themes on the basis of initial indexing, hierarchical grouping of codes and discussion of individual transcripts. The effects of patient characteristics (gender, age, type of medication experienced and expectations) were explored in the analysis. Interpretation of the findings was verified using independent transcript analysis by the authors and research team discussions, including the lay members.

\section{Results}

The themes presented here follow the trajectory of the participants' experience from initial triggers to seek help and prior expectations; through the experiences of adapting to the prescribed medication and their perceptions of the support they received. Participants' reflections on their experience and the recommendations for service improvement are also presented. The quotes below give a fair representation of the data and names have been changed to protect anonymity of the participants.

\section{Triggers for considering anti-obesity drugs}

Most participants reported their main reason for seeking medical help for weight loss was their current or future health. To regard as anti-obesity drugs was often reinforced by advice from a health professional.

I told him I were worried about me weight, obviously, I mean I've had two heart attacks actually, I've got arthritis, and he's [the doctor] forever telling me I ought to be losing weight. [Gareth (64 years); Orlistat]

So the surgeon said it would be better for me in the long run if I lost some weight, not that he wouldn't operate but 'it would help me'... [Eva (37), all three meds].

However, a few participants were more concerned about their appearance and body image, prompted by contacts with friends or family.
I think what started it all, my friend had a gastric band put in and she lost 7 stone and she started looking younger again and I thought, oh God it's my weight that's ageing me so I'll try and do something about my weight and-well I think that's what kicked it off. [Pauline (53), all three meds]

\section{Prior expectations}

The majority of participants expected to lose weight with anti-obesity drugs. Some were realistic in their expectations, in that they would help them to lose weight but not dramatically. However, some had overly high expectations of these drugs in terms of weight loss and others had felt sceptical of the drugs' effectiveness. Typically most participants had felt ambivalent about taking weight loss medication.

That they would, I suppose just support what I was trying to do, that it would really help, not be a miracle cure but help.

[Phillipa (52), Orlistat, Sibutramine]

Well, I expected the weight loss to be more dramatic than it is. [Clifford (62), Orlistat]

I think I was a bit sceptical, they don't help. [Eva (37), all three meds]

I suppose it's like with any medication, you just expect it to work instantly don't you, and it's not power drug, I know that much, do you know what I mean? I don't think it's in an instant going to make you thin, which obviously, when you take medication, that's what you expect, ain't it? And I was there, that's what I expected, but in reality it doesn't work like that. [Daphne (42), Orlistat]

\section{Knowledge of the medication}

All participants prescribed Orlistat reported they were aware that there is a close relationship to fat intake and the decreased absorption of fat from the body. In addition, those who experienced the gastrointestinal effects of Orlistat explained it reinforced their understanding of its mode of action.

Well, I think that were only if I'd eaten like too much fat, you know. It just came out like, it was like somebody had dropped a drop of oil in toilet. But I presume that's what they were there to do. ...Stops your body 
absorbing fat so it's got to come out somewhere, hasn't it. [Charlotte (47), Orlistat]

However, the participants who were prescribed Sibutramine and Rimonabant appeared to lack an understanding of their mode of action. Although, three participants knew that these drugs have an effect on appetite, they did not clearly experience a decrease in their appetite.

But I never felt that [sibutramine] made me feel full [...] But these have been, I just don't know, I didn't know how they've worked but they have worked. [Faith (49), Sibutramine]

\section{Perceptions of initial prescription}

Participants in this study reported that the GP gave little or no information around anti-obesity drugs and the necessary lifestyle changes. It was also clear that they were rarely given the choice of anti-obesity drugs or any other weight loss treatment and it appeared that the decision of treatment was mainly of the GP.

I just mentioned was there anything that they could do to help me and they just described this tablet and I went ahead with it. ... [Abigail (58), Orlistat, Sibutramine]

\section{Adapting to the medication}

Participants' experienced common side effects with all anti-obesity drugs, however, these varied in degree and type for each individual. The majority changed their diet and eating patterns or adopted other coping strategies to avoid the side effects. These strategies were particularly when participants were at work or going out and included staying close to a toilet, omitting medication and avoiding eating or watching what they are eating.

I thought, I can't have this in work, this is not good for me, running to the toilet every five minutes. And so, I would only take them, Friday, Saturday, Sunday, the days I don't work, and then I didn't take them in the week when I was at work, because I was scared to in case I needed the toilet.

$$
\text { [Julie (45), Orlistat] }
$$

I just tended to have drinks, [...] so I tended to, if I was hungry, I just had coffee.... [Agnes (61), Orlistat]
Eight participants stated that the medications did not change their lifestyle because they were already following a healthy diet. However, most participants felt that the anti-obesity drugs changed their lifestyle, positively in some respects and negatively in others. The positive changes were an improvement in their diet and physical activity; but for some, changes to diet and other social activities like going out were viewed as negative.

So yes it did have an effect on the way you live. And it sort of took any social eating out of your life because you couldn't go, or you didn't take the tablet, you know, so that's what I did, stopped taking the tablets when I was going out.

\section{[Phillipa (52), Orlistat, Ssibutramine]}

Nine participants described experimenting with their medication to test its effectiveness in weight loss. These participants stopped and restarted the medication, altered the dose or changed the timing of medication.

I started to take two a day, and they were right good, it were really good... and then weight were just coming off right easy...

[Kate (50), Orlistat, Sibutramine]

Participants prescribed Orlistat found it difficult to remember to take the tablets, usually at lunchtime particularly when they were out of home. Also, three participants reported they would take less than three tablets per day if they missed a meal. In contrast, those prescribed Sibutramine and Rimonabant found them convenient to take, as they only had to take one tablet a day.

\section{Experiences of primary care support}

Participants had mixed feelings about the quality of the support received from the primary care services. Most participants had regular reviews from practice staff and monitoring of their weight and blood pressure and over half of them remembered receiving specific advice on diet. Although, the majority of participants felt satisfied with the support offered by practice staff, five of them felt that there should be more than what was on offer and three felt unsure of what kind of support they could reasonably access. 
Well, I didn't, I didn't have any support really, not from my GPs practice. I think it was just a case of, you know, here's some tablets, go and take them for a trial period, and away you go. [Stewart (44), Orlistat]

Oh my doctor's been brilliant; I can't fault her at all. She's been very, very good. I see her every month. She was the one who suggested these tablets. If ever I need to contact her, I'm allowed to. She's phoned me at home before today, you know, fantastic, I can't say the support wasn't anything but really really good. [Julie (45), Orlistat]

Well, I kept going to my doctor; I went once a month, so I mean that was really good. ... I mean I don't know I felt when I was taking it, I thought somebody was bothered, that people were bothered about my health and it wasn't just like up to me to, you know, I'd got support like from my doctor and like nursing practice. And I mean by going in like every month I knew I'd got to do it otherwise I'd have been letting everybody down, you know, as well as myself.

[Samantha (45), Orlistat]

So I don't know whether he's supposed to offer it or not but I'm sure if I went in and asked, I mean he always sits and talks to me, he's good in that way. But I don't think I've ever asked for anything, you know.

[Gareth (64), Orlistat]

Only four participants were aware of the support offered by the drug companies, but also had mixed feelings about this.

...the people from MAP who deal with this Orlistat they phone me occasionally, but even then, the only thing they tell me to do is to do a bit of exercise with some cans of beans and move my arms about for twenty minutes a day or something like that.... [Robert (67), Orlistat]

\section{Patients' perceptions of outcomes}

Eleven participants lost weight with the antiobesity drugs but were ambivalent about their effectiveness in their weight loss. They felt that the weight loss was due to other factors such as changes in their diet or physical activity levels, or due to increased support from others.
Well I have lost weight, so they must work, unless it is just psychological because I've been doing Slimming World, so I don't know. [Faith (49), Sibutramine]

Well, it worked for me. Whether it were just fact that I was watching every bit of fat that I ate....

[Charlotte (47), Orlistat]

Participants whose weight remained stable or increased, thought that either the medication did not work or their current lifestyle or other medication(s) prevented it from being effective.

I mean I'd kept on a diet as such, and it didn't, I wasn't losing weight, ... so I thought probably I'm eating wrong or ... I thought these diabetic tablets what I'm on, are they doing something. So again it's a bit frustrating being on all these tablets and not knowing whether they're going against whatever I take.. [Rachel (70), Orlistat]

In general, those participants who consciously changed their lifestyle and diet managed to lose weight regardless of the type of medication or their experience of side effects. Those who did not change their lifestyle or who experimented with the tablets did not lose weight. An exception to the latter finding was Kate, who had increased her initial dose of $10 \mathrm{mg}$ of Sibutramine. In addition, those with very high expectations generally did not lose weight.

Participants who lost weight experienced positive feelings such as increased self-confidence, happiness, increased determination and generally feeling good in themselves. Participants who did not lose weight reported negative feelings such as disappointment, frustration, embarrassment and blamed themselves for the medication not working.

But I was more disappointed in myself than the drug because I felt that it's me that's got to do it, not the drug. ...I told [the doctor] I've stopped but I felt embarrassed going back to him because he's helped me and I've not helped him, or that's how I felt.

$$
\text { [Christopher (43), Orlistat] }
$$

\section{Recommendations to improve support}

Almost half of the participants suggested that more information should be provided around antiobesity drugs' mode of action, side effects, dose, 
duration and necessary lifestyle changes. They also suggested that they should be given a choice of medication and support in making lifestyle changes and overcoming unpleasant side effects.

Seven participants suggested that expectations should be addressed from the start of the treatment.

I'd just like to think that people are getting the understanding and, you know, they know what's expected from the tablets and they know what's expected from them.

$$
\text { [Alexandra (53), Orlsitat] }
$$

Half of the participants identified a range of health professionals that could support them while taking anti-obesity drugs, as well as, the type of support such as regular reviews of weight and blood pressure and opportunity to discuss their experiences with the medication.

So I suppose some support would have been better, might have felt more, that I could go back and talk about the diarrhoea or I could go and talk about the constipation, with somebody that wasn't because I don't like to go into the doctor's and tie his time up. If I could go and see the nurse or a dietitian, a dietitian would be nice then that would have helped I think, yes that would have helped.

\section{[Phillipa (52), Orlistat, Sibutramine]}

In addition, six participants suggested that group support would be beneficial:

...to help people even further it would be better if there was some kind of group maybe outside the doctors or maybe, I don't know, in a health centre or somewhere where they could go to for that additional support and meet other people that was struggling as well. [Sally (45), Orlistat]

Five participants expressed their disappointment with health professionals not helping or being understanding. This was either by direct experience of the participant or what they perceived health professionals' attitudes are towards overweight and obese people.

...it just annoys me so much that the sort of medical people look at people and judge, because they shouldn't be like that at all. [Clare (26), Sibutramine]

I think in general, the perception of overweight people, it's automatically accepted that people that's overweight sit there and stuff half a dozen Mars bars and this, that and other. Well that gets my back up because I just do not stuff and gorge like that. And I do think that overweight is a problem that they've not hit on yet.

$$
\text { [Abigail (58), Orlistat, Sibutramine] }
$$

\section{Discussion}

\section{Summary of main findings}

Health concerns are the key factor for most patients seeking help with weight loss from their GP practice. However, a few have concerns about their body image and appearance. Patients are typically ambivalent about taking anti-obesity dugs and expectations vary hugely from unreasonably sceptical to unreasonably optimistic. However, there appears to be high awareness that these drugs must be combined with lifestyle changes. Although patients on Orlistat understood how this worked, those on Sibutramine and Rimonabant did not.

Participants' experience in taking anti-obesity drugs varied greatly and changed with experiences of weight loss, side effects and quality of support. Their actions and feelings appeared to be related mainly to ongoing weight loss experience. Participants who were losing weight adapted or persevered with the medication; participants who did not lose weight tested the medication or abandoned it and typically expressed disappointment. Most could identify points at which the information, choice and support provided by primary care could be improved for them and other patients taking anti-obesity drugs. However, most were not aware of other avenues of support with anti-obesity medication.

\section{Strengths and limitations of this study}

There has been little previous research of patient experiences of anti-obesity drugs, and this is the only study currently in this field focusing on all three anti-obesity drugs, including Sibutramine and Rimonabant. This study was successful in sampling people with varied backgrounds and experiences and it provides a useful insight into the perceptions of this group. The focus on typical primary care 
contexts is useful for practice and service development in the UK and elsewhere. The involvement of lay representatives in the study team strengthened the design of data collection tools and the relevance of data analysis (Staley, 2009).

However, this was a small study, recruiting participants from only three GP practices in one part of the UK. Only about a quarter of approached patients responded to the invitation to participate. The accounts of these participants are perhaps particularly open to recall bias, since a relatively long period (up to two years) might have elapsed since their experience of initial prescription. Therefore, generalisations and broader conclusions remain tentative. Within the sample, most participants persevered with the prescription, showing a good level of adherence. The degree to which this is typical of all patients initiated on a prescription is not known. Fewer men than women were included in the study and most participants' experience was of Orlistat rather than other anti-obesity drugs.

\section{Comparison with existing literature}

In line with other research (Dalle Grave et al., 2004; Tod and Lacey, 2004), this study found that health concerns are the key reason for seeking help with weight but also that a minority are motivated by body image or appearance. The finding of ambivalence about medication is widely found in other research about experiences of medications in general (Pound et al., 2005). Patients with long-term conditions typically feel ambivalent about taking drugs (Townsend et al., 2003). Although there is limited research reporting specifically on the perceptions of patients who have been prescribed anti-obesity drugs there is other evidence of ambivalence for patients seeking support with weight loss in primary care (Brown et al., 2006). The condition of obesity adds a further layer of ambivalence to the typical ambivalence with medication.

Ogden and Sidhu (2006) showed that patients receiving Orlistat adhered to the medication and changed their behaviour when they experienced side effects if their health was their primary concern. However, others did not adhere to the medication, put off by its side effects and did not change their diet if their sole concern was their appearance. These findings are in contrast to our study, where patients persevered with the medication if they experienced weight loss.
It is not surprising that patients who were prescribed anti-obesity drugs expected to lose weight, and that some had overly high expectations. Previous research shows that obese individuals have unrealistic weight loss expectations of weight management treatment. They usually expect to lose about $25 \%-35 \%$ of their body weight (Jeffrey et al., 1998; Foster et al., 2001) even after receiving information that they would probably lose $5 \%-15 \%$ of their weight with drug and/or lifestyle changes (Wadden et al., 2003). On the other hand, the evidence is that antiobesity drugs only modestly reduce weight (Franz et al., 2007).

It has been observed in this study and elsewhere that patients taking anti-obesity drugs modify the regime for various reasons (Fox et al., 2005). In general, it appears patients who change or modify their dose of medications, do so because of their experiences regarding the efficacy, safety and value in terms of health outcome (Pound et al., 2005; Gordon et al., 2007).

Patient information, choice and support were identified as issues in this study and these findings are reflected elsewhere in the literature. For instance, a study of GPs showed that they discussed medications (mode of action, side effects, contraindications and choice of alternative medication) in less than $20 \%$ of new prescriptions. Treatment duration was only discussed in under $40 \%$ and dosage in $64 \%$ of the medications (Richard and Lussier, 2006). On the other hand, patients find such information about medications essential (Raynor et al., 2004). It is important to note that patients may have been given the information but only recall part of it (Ley, 1988).

Other research also suggests that patients have mixed feelings about the support on offer for obesity. It is apparent that satisfaction with primary care services in general is good, but in relation to obesity, satisfaction can be low and this may prevent overweight patients from seeking help and taking up support (Brown et al., 2006). Findings about participants' suggestions for improving services are also reflected in other research and focused on obese patients receiving weight loss advice from their GP (Potter et al., 2001). In addition, a consistent finding is that a proportion of individuals favour group interventions for support (Roberts and Ashley, 1999; Brown et al., 2006). 


\section{Box 2 Key recommendations for ser- vice improvement}

- Initial assessment: clarify patients' perceptions of their obesity, reasons for seeking medical help and expectations of antiobesity drugs.

- Information provision: ensure clear understanding of medications mode of action, side effects, dose/regime, duration and associated lifestyle changes.

- Quality of ongoing support: provide followup appointments for monitoring and addressing difficulties with medication and/ weight loss and suggest other avenues for support (nurse, dietitian, group therapy and exercise on prescription).

- Transitions in coming off medication: be aware of patients' weight concerns after discontinuation of medication and guide patients to suitable alternative support.

- Attitudes: address attitudes of primary care staff, if necessary, to improve patients' perceptions about negative attitudes associated with obesity stereotypes.

\section{Implications for clinical practice}

In the UK, the government has set out an ambitious strategy to tackle obesity (Department of Health, 2008) and to improve the personalised support and advice for people who are obese. Primary care prescribing of anti-obesity drugs is currently a key element of personalised support and one that is likely to expand in the coming years. This study suggests that the quality of this support could be considerably improved. This includes more sensitive prescribing. For example, it has been proposed that considering the type of patient according to their psychological profile (Elfhag et al., 2008), associated medical conditions (diabetes, heart disease and hypertension), lifestyle (Lean and Mullan, 2007) and past experiences and beliefs around antiobesity drugs will help clinicians to choose the right drug for their patients (Ramstrom et al., 2006).

In addition, better understanding of patient expectations around anti-obesity drugs should help the NHS to shape services to meet needs and make the experiences of patients more positive (Nunes et al., 2009). This study has identified a number of areas for service improvement (Box 2), which could play an important role in improving treatment and enhancing individuals' experiences of support in primary care.

\section{Acknowledgements}

The authors thank the study's lay representatives Fiona Claydon and Linda Crosby for their valuable contribution. They also thank the primary care teams who helped them recruit patients and the individual volunteers who participated in the study.

\section{Declaration}

Approval for the study was given by Hull and East Riding NHS Local Research Ethics Committee (REC: 07/Q1104/13) and South Sheffield NHS Local Research Ethics Committee.

\section{Funding Body}

Sheffield Health and Social Research Consortium (Reference: ZG58).

\section{Competing interests}

None.

\section{References}

Brown, I., Thompson, J., Tod, A. and Jones, G. 2006: Primary care support for tackling obesity: a qualitative study of the perceptions of obese patients. British Journal of General Practice 56, 666-72.

Counterweight Project Team. 2005: Obesity impacts on general practice appointments. Obesity Research 13, 1442-49.

Dalle Grave, R., Calagi, S., Magri, F., Cuzzolaro, M., Dall'Aglio, E., Lucchin, L., Melchionda, N. and Mrachesini, G., the QUOVADIS Study Group. 2004: Weight loss expectations in obese patients seeking treatment at medical centres. Obesity Research 12, 2005-12.

Department of Health. 2005: Choosing health: making healthy choices easier. London: The Stationary Office, Department of Health.

Department of Health. 2006: Care pathway for the management of overweight and obesity. London: Department of Health.

Department of Health. 2008: Healthy weight, healthy lives: a cross government strategy for England. Crown: Department of Health.

Dr Foster. 2005: Your guide to better health: primary care management of adult obesity. Retrieved June 2007 from http://www.drfosterintelligence.co.uk/library/reports/ obesityManagement.pdf). 
Elfhag, K., Finer, N. and Rossner, S. 2008: Who will lose weight on Sibutramine and Orlistat? Psychological correlates for treatment success. Diabetes, Obesity and Metabolism 10, 498-505.

Foresight. 2007: Tackling obesities: future choices - project report, Second edition. Government Office for Science. http://www.foresight.gov.uk

Foster, G.D., Wadden, T.A., Phelan, S., Sarwer, D.B. and Sanderson, R.S. 2001: Obese patients' perceptions of treatment outcomes and the factors that influence them. Archives of Internal Medicine 161, 2133-39.

Fox, N.J., Ward, K.J. and O'Rourke, A.J. 2005: The "expert patient": empowerment or medical dominance? The case of weight loss, pharmaceutical drugs and the Internet. Social Science of Medicine 60, 1299-309.

Franz, M.J., VanWormer, J.J., Crain, L., Boucher, J.L., Histon, T., Caplan, W., Bowman, J.D. and Pronk, N.P. 2007: Weight-loss outcomes: a systematic review and meta-analysis of weight loss clinical trials with a minimum 1-year follow-up. Journal of American Dietetic Association 107, 1755-67.

Gordon, K., Smith, F. and Dhillon, S. 2007: Effective chronic disease management: patients' perspectives on medication-related problems. Patient Education and Counselling 65, 407-15.

Jeffrey, R.W., Wing, R.R. and Randall, R.M. 1998: Are smaller weight losses or more achievable weight loss goals better in the long-term for obese patients? Journal of Consulting Clinical Psychology 66, 641-45.

Lean, M. and Mullan, A. 2007: Obesity: which drug and when? International Journal of Clinical Practice 61, 1555-60.

Ley, P. 1988: Communication with patients. London: Croom Held Ltd.

MHRA. 2008: MHRA Drug Alerts. Rimonabant (Acomplia): suspension of marketing authorisation as risks outweigh benefits. Retrieved 23 October 2008 from http://www.mhra. gov.uk

National Audit Office. 2001: Tackling obesity in England. London: The Stationary Office.

National Institute for Health and Clinical Excellence. 2006: Obesity: the prevention, identification, assessment and management of overweight and obesity in adults and children. London: NICE.

Nunes, V., Neilson, J., O'Flynn, N., Calvert, N., Kuntze, S., Smithson, H. et al. 2009: Clinical guidelines and evidence review for medicines adherence: involving patients in decisions about prescribed medicines and supporting adherence. London: National Collaborating Centre for Primary Care and Royal College of General Practitioners.

Ogden, J. and Sidhu, S. 2006: Adherence, behaviour change and visualisation: a qualitative study of the experiences of taking an obesity medication. Journal of Psychosomatic Research 61, 545-52.

Padwal, R.S. and Majumdar, S.R. 2007: Drug treatments for obesity: orlistat, sibutramine and rimonabant. Lancet 369, 71-77.
Potter, M.B., Vu, J.D. and Croughan-Minihane, M. 2001: Weight management: what patients want form their primary care physician. Journal of Family Practice 50, 513-18.

Pound, P., Britten, N., Morgan, M., Yardley, L., Pope, C., Daker-White, G. and Campbell, R. 2005: Resisting medicines: a synthesis of qualitative studies of medicine taking. Social Science of Medicine 61, 133-55.

Ramstrom, H., Afandi, S., Elofsson, K. and Petersson, S. 2006: Differences in beliefs between patients and pharmaceutical specialists regarding medications. Patient Education and Counselling 62, 244-49.

Raynor, D.K., Savage, I., Knapp, P. and Henley, J. 2004: We are the experts: people with asthma talk about their medicine information needs. Patient Education and Counselling 53, 167-74.

Richard, C. and Lussier, M. 2006: Nature and frequency of exchanges on medications during primary care encounters. Patient Education and Counselling 64, 207-16.

Richie, J. and Lewis, J. 2003: Qualitative research practice. London: Sage Publications.

Richie, J., Spencer, L. and O'connor, W. 2003: Carrying out qualitative analysis. In Richie, J. and Lewis, J., editor, Qualitative research practice, Ch 9. London: Sage Publications. 219-62.

Roberts, A. and Ashley, G. 1999: What are the characteristics of overweight and obese patients who achieve weight loss and what factors are most helpful? A quantitative and qualitative study of patients and interventions in a rural general practice. Journal of Human Nutrition and Dietetics 12(Suppl 1), 20-27.

Rucker, D., Padwal, R., Li, S.K., Curioni, C. and Lau, D.C.W. 2007: Long term pharmacotherapy for obesity and overweight: updated meta analysis. British Medical Journal 335, 1194-99.

SPC. 2007: Summary of product characteristics for reductil $10 \mathrm{mg}$ and $15 \mathrm{mg}$. Retrieved November 2009 from http:// emc.medicines.org.uk

SPC. 2006: Summary of product characteristics for acomplia $20 \mathrm{mg}$ film-coated tablets. Retrieved June 2007 from http:// emc.medicines.org.uk

SPC. 2009: Summary of product characteristics for xenical $120 \mathrm{mg}$ hard capsules. Retrieved November 2009 from http://emc.medicines.org.uk

Staley, K. 2009: Exploring impact: public involvement in NHS, Public Health and Social Care Research. Eastleigh: INVOLVE.

Tod, A.M. and Lacey, A. 2004: Overweight and obesity: helping clients to take action. British Journal of Community Nursing 9, 59-66.

Townsend, A., Hunt, K. and Wyke, S. 2003: Managing multiple morbidity in mid-life: a qualitative study of attitudes to drug use. British Medical Journal 327, 837-42.

Wadden, T.A., Womble, L.G., Sarwer, D.B., Berkowitz, R.I., Clark, V.L. and Foster, G.D. 2003: Great expectations: "I'm losing $25 \%$ of my weight no matter what you say". Journal of Consulting Clinical Psychology 71, 1084-89. 